\title{
A Talon Cusp on Fused Teeth Associated with Hypodontia: Report of a Unique Case
}

\author{
Dinesh Rao Ba \\ Sapna Hegde
}

\section{ABSTRACT}

Fusion and talon cusps are rare developmental dental anomalies affecting both primary and permanent dentitions. Talon cusps normally occur on the palatal surface of permanent maxillary incisors, while fused teeth are more common in the primary anterior dentition. An understanding of these dental anomalies and their associated problems are important to provide prophylactic measures, thereby preventing or minimizing possible complications. This paper presents a unique case of fused mandibular permanent incisors with a lingual talon cusp associated with hypodontia of an adjacent tooth. (Eur J Dent 2010;4:75-80)

Key words: Talon cusp; Dental fusion; Hypodontia; Dental anomalies.

\section{INTRODUCTION}

Development of the human dentition is a very complex process. Any aberrations in the different stages of tooth development can result in unique manifestations, either in the primary or in the permanent dentition. The terms "double teeth", "double formations", “joined teeth", "fused teeth"1

a Associate Professor, Pacific Dental College \& Hospital, Department of Pediatric Dentistry, Rajasthan, India.

b Professor \& Head, Pacific Dental College \& Hospital, Department of Pediatric Dentistry, Rajasthan, India. Running title: A talon cusp on fused teeth

- Corresponding author: Dr. Dinesh Rao B Pacific Dental College \& Hospital, Department of Pediatric Dentistry

Debari, Udaipur - 313024, Rajasthan, India.

Phone: +919414158235, +912942493109

Fax: +912942491508

E-mail: dineshraodrediffmail.com or "dental twinning" 2 are often used to describe fusion or gemination, both of which are primary developmental abnormalities of the teeth.

Fusion is a rare developmental disorder characterized by the union of two adjacent teeth at the crown level (enamel and dentin), causing the formation of a tooth with an enlarged clinical crown. Incidence of this anomaly is approximately $0.1 \%$ in the permanent and $0.5 \%$ in the primary dentition. However, reports of its distribution according to gender, race and location are conflicting in literature. ${ }^{3}$

Fusion may be partial or total, depending on the stage of tooth development at the time of union. Both of the conjoint buds may be normal, or one may be supernumerary. A fused tooth usually has two separate root canals and a single wide crown. 
There may be one pulp chamber divided into two root canals or two independent endodontic systems. Clinically, the crowns of the teeth appear to be melded together, with a small groove between the mesial and distal sections. ${ }^{4}$

Talon cusp is a morphologically well-delineated accessory cusp-like structure projecting from the cingulum area or cementoenamel junction towards the incisal ridge of the maxillary or mandibular anterior teeth in both the primary and permanent dentitions. This anomalous structure is composed of normal enamel, dentin and varying extension of pulp tissue. ${ }^{5}$

The term talon cusp was coined by Mellor and Ripa $^{6}$ due its resemblance to an eagle's talon. The diverse clinical manifestations of the anomaly, have led the talon cusp to be described in many different ways: exaggerated cingula, cusp-like hyperplasia, accessory cusp, supernumerary cusp, interstitial cusp. ${ }^{7}$ The prevalence of talon cusps is low, with an incidence of less than $0.06 \%{ }^{8}$ to approximately $8 \%$ of the population.

Due to a wide variation in the size and shape of talon cusp and in order to have diagnostic criteria, Hattab et $\mathrm{al}^{10}$ classified the anomaly into three types:

Type 1 (Talon): a morphologically well-delineated additional cusp that prominently projects from the palatal (or facial) surface of a primary or permanent anterior tooth and extends at least half the distance from the cement-enamel junction to the incisal edge.

Type 2 (Semi talon): an additional cusp of a millimeter or more but extending less than half the distance from the cement-enamel junction to the incisal edge. It may blend with the palatal surface or stand away from the rest of the crown.

Type 3 (Trace talon): an enlarged or prominent cingula and their variations, i.e. conical, bifid or tubercle-like.

Even though hypodontia is a common trait in modern populations, often encountered by dental practitioners, its prevalence is as low as $1-2.2 \%$ in the mandibular incisor region. ${ }^{7} A$ tooth may be considered to be developmentally missing when it cannot be discerned clinically or radiographically and no history exists of its extraction. Dhanraja$\mathrm{ni}^{11}$ classified hypodontia according to the severity of the condition. The term "mild-to-moderate hypodontia" is used to denote agenesis of teeth up to five, while the absence of six or more teeth, excluding the third molars, indicates "severe hypodontia".

This article describes a unique case of a lingual talon cusp on fused permanent mandibular incisors associated with hypodontia of an adjacent tooth.

\section{CASE REPORT}

An eleven year-old male visited the Department of Pediatric Dentistry at the Pacific Dental College \& Hospital, Udaipur, India, for routine dental checkup. The medical and dental histories were noncontributory. On extraoral examination, the patient had a symmetrical straight facial profile. Intraorally, a mixed dentition was observed with fair oral hygiene and dental caries in the mandibular right second primary molar. The upper arch was $\mathrm{U}$-shaped, whereas the lower arch was parabolic, with the midline shifted to the right. The molar relationship was Angle's class I on either side. Clinically, only two incisors were seen in the mandibular arch, one with increased mesiodistal coronal width of $9.5 \mathrm{~mm}$. (Figure 1).

In the anterior region of the mandible, a double tooth was observed with pyramidal-shaped cusplike projections from the lingual surface, extending to more than half the height of the tooth crown (Figures 2 and 3). Clinically, the crowns of the teeth appeared to be melded together, without any distinct labio-lingual groove. The fused teeth were clinically asymptomatic. Although, the talon cusp neither irritated the tongue during speech and mastication nor interfered with occlusion, the patient complained of the bulkiness in the area. Esthetics was compromised because of the large size of one tooth and the absence of another. Neither the parent nor the patient could recall any similar anomalies in the primary dentition. No other family members were known to have the same trait.

Periapical radiograph of the double tooth revealed two separate root canals terminating in two apical foramina that emanated from a conjoint pulp chamber. The talon cusp resembled a $V$-shaped structure superimposed on the image of the affected crown (Figure 4).

Panoramic radiograph showed the presence of a normally developed permanent dentition except for the lower right central incisor, which was 
found to be congenitally absent (Figure 5).

Based on the clinical and radiographic findings, lingual talon cusp type 1 described by Hattab et $\mathrm{al}^{10}$ on fused permanent mandibular incisors associated with hypodontia of an adjacent tooth has been diagnosed.

Oral hygiene prophylaxis was performed to improve the patient's oral hygiene. With parental consent, a periodic reduction of the talon cusp was carried out at 6-8 week intervals, using a diamond bur in a high-speed water-cooled handpiece. Following each grinding procedure, the exposed surface was treated with fluoride varnish as a desensitizing agent. In addition, the patient was scheduled for periodic dental examination.

\section{DISCUSSION}

Fused dentition and talon cusps are developmental anomalies with inherently bizarre anatomy. These anomalies may develop during tooth bud morpho-differentiation as a result of a

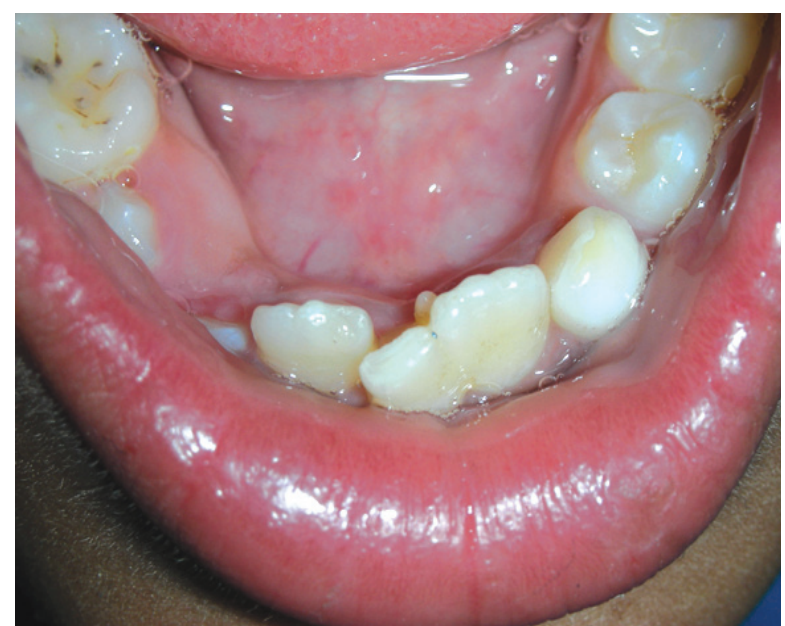

Figure 1. Occlusal view showing fused dentition with talon cusp.

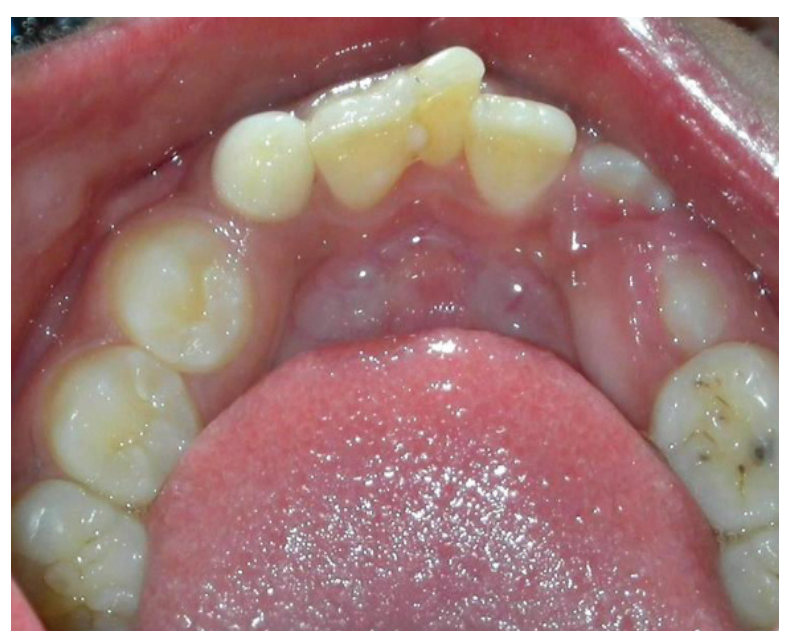

Figure 2. Lingual view of the fused teeth. developmental aberration of both the ectoderm and mesoderm. Several mechanisms have been proposed to explain the etiology of fusion including the influence of pressure or physical forces producing close contact between two developing teeth, necrosis of epithelial tissue between two developing teeth, embryological persistence of the interdental lamina between two germs, genetic predisposition, and environmental factors such as thalidomide embryopathy, fetal alcohol exposure, or hypervitaminosis $A$ of the pregnant mother. It may also occur with several syndromes such as achondrodysplasia, chondroectodermal dysplasia, focal dermal hypoplasia, and osteopetrosis. ${ }^{12}$

Brook and Winter ${ }^{1}$ elucidated the difficulty of deciding whether a tooth is fused or geminated and proposed that these anomalies be referred to in a neutral term, such as "double teeth". Definite categorization of joined teeth as either gemination or fusion however is often difficult. Several clinical and radiographic criteria are used to distinguish fusion from gemination, such as morphology of the crown and the pulp chamber, location, and number of teeth.

Fusion is the incomplete attempt of two tooth buds to fuse into one, whereas gemination is the incomplete attempt of one tooth bud to divide into two. Hence the tooth count in gemination will show a full complement of teeth, while in fusion, the tooth count of the arch is one tooth less. ${ }^{12}$ Clinically, gemination results in a bifid crown, with the coronal halves appearing as mirror images, whereas fusion takes place at an angle causing the tooth to have a crooked appearance. Radiographic examination reveals usually two separate

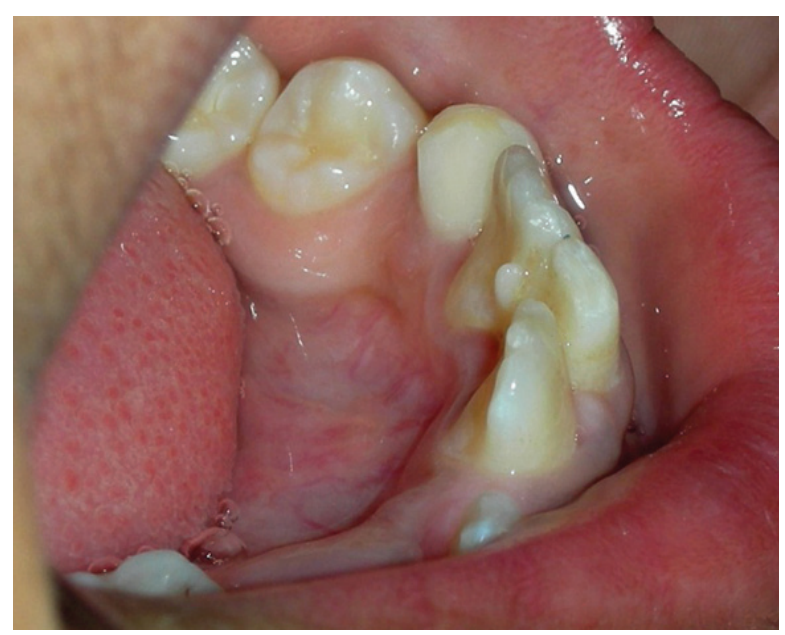

Figure 3. A side view showing fusion and talon cusp. 
canals in case of fusion, whereas in gemination there is usually one large conjoint root canal. After careful clinical and radiographic evaluations, we judged the double tooth in the present case report to be most likely a fusion of the permanent left mandibular central and lateral incisors. It had two separate root canal systems, and no supernumerary teeth were present in the arch.

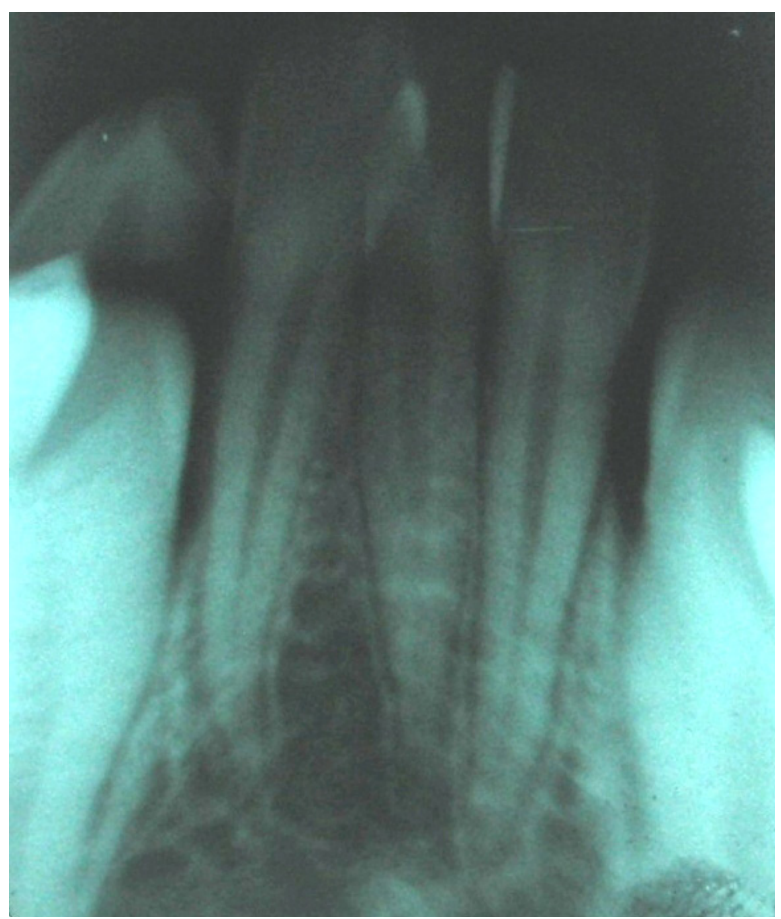

Figure 4. Periapical radiograph of the fused teeth, showing two separate roots.
Similar to fusion, talon cusps are believed to originate during the morpho-differentiation stage of tooth development, as a result of an outward folding of the inner enamel epithelial cells and a transient focal hyperplasia of the mesenchymal dental papilla. ${ }^{10}$ The exact etiology of talon cusps is yet to be known; however, there is strong support for a multifactorial etiology, involving both genetic and environmental factors. They have also been reported in patients with Mohr syndrome, ${ }^{13}$ Sturge-Weber syndrome, ${ }^{14}$ Rubinstein-Taybi syndrome, ${ }^{15}$ cleft lip and palate, ${ }^{16}$ incontinentia pigmenti achromians, ${ }^{17}$ hypomelanosis of Ito, ${ }^{18}$ Ellisvan Creveld syndrome ${ }^{19}$ and Alagille's syndrome. ${ }^{20}$

Tooth development is a complex process, in which reciprocal and sequential interactions between epithelial and mesenchymal cells regulate the cell activities like proliferation, condensation, adhesion, migration, differentiation and secretion, which lead to the formation of a functional tooth organ. Any aberration among these will result in tooth ageneses, the most common type of craniofacial malformations. ${ }^{21}$ Although tooth agenesis is occasionally caused by environmental factors, in the majority of cases hypodontia has a genetic basis. In familial hypodontia, the type of inheritance in the majority of families seems to be autosomal dominant with incomplete penetration and variable expressivity.22

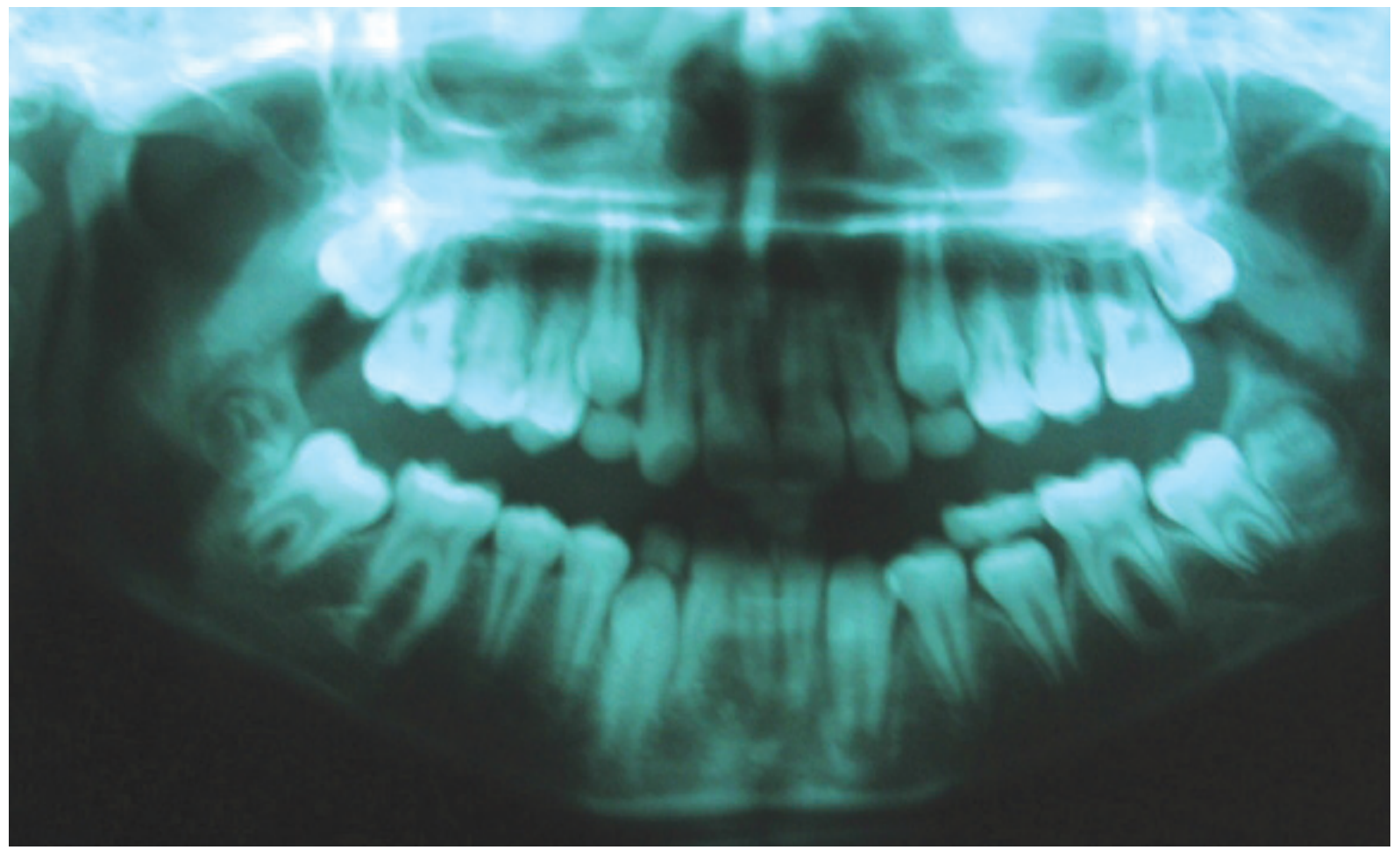

Figure 5. Panoramic radiograph showing hypodontia of mandibular right central incisor. 
Mandibular talon cusps are less common when compared to $94 \%$ involvement of maxillary dentition. ${ }^{7}$ On the other hand, fused dentition exhibiting a talon cusp is extremely rare. ${ }^{3,23}$ Although talon cusp has been associated with other dental anomalies elsewhere in the oral cavity, ${ }^{24}$ only one case of talon cusp with hypodontia of adjacent tooth has been reported in the literature. ${ }^{25}$ The striking uniqueness of the present case is the concomitant occurrence of fusion and talon cusp with single tooth hypodontia involving the adjacent tooth, which strongly points to an interplay of multiple etiological factors.

Asymptomatic anterior fusion should be left alone unless problems arise with esthetics, spacing, and dental caries. Simple composite restorations can be used to camouflage and prevent caries developing in the fissures ${ }^{26}$ Invasive treatment such as selective grinding and surgical hemisection may compromise the pulpal status and should be deferred until the root apex is mature. ${ }^{4}$

The treatment of talon cusp requires careful clinical judgment and is dependent on its size and shape. Management includes no treatment, sequential grinding, pit and fissure sealing, pulp therapy, restorative treatment, full crown coverage and extraction of the affected tooth. ${ }^{5}$

In the present case, gradual reduction of the talon cusps was carried out, at 6-8 week intervals to allow the deposition of reparative dentin to preserve pulpal vitality. Because most of the odontoblasts lie along the length of the cusp, ${ }^{27}$ grinding was done on the side of the cusp to initiate reparative dentin deposition.

\section{CONCLUSIONS}

It is important for dental professionals to be familiar with common dental developmental anomalies. Patients should be properly informed of the potential risk factors and problems associated with these anomalies. Early diagnosis of and appropriate treatment approaches to dental anomalies can minimize possible complications.

\section{REFERENCES}

1. Brook AH, Winter GB. Double teeth. A retrospective study of 'geminated' and 'fused' teeth in children. Br Dent $J$ 1970;129:123-130.

2. Chaudhry SI, Sprawson NJ, Howe L, Nairn RI. Dental twinning. Br Dent $J$ 1997;182:185-188.
3. de Siqueira VC, Braga TL, Martins MA, Raitz R, Martins MD. Dental fusion and dens evaginatus in the permanent dentition: literature review and clinical case report with conservative treatment. J Dent Child 2004;1:69-72.

4. Hülsmann M, Bahr R, Grohmann U. Hemisection and vital treatment of a fused tooth- literature review and case report. Endod Dent Traumatol 1997;13:253-258.

5. Hattab FN, Yassin OM, Al-Nimri KS. Talon cusp- Clinical significance and management: Case reports. Quintessence Int 1995;26:115-120.

6. Mellor JK, Ripa LW. Talon cusp: a clinically significant anomaly. Oral Surg Oral Med Oral Pathol 1970;29:225-228.

7. Danker E, Harari D, Rotstein I. Dens evaginatus of anterior teeth; literature and radiographic survey of 15,000 teeth. Oral Surg Oral Med Oral Pathol 1996;81:472-476.

8. Sedano HO, Freyre IC, Garza De La Garza ML, et al. Clinical orodental abnormalities in Mexican children. Oral Surg Oral Med Oral Pathol 1989;68:300-311.

9. Chawla HS, Tewary A, Gopalakrishnan NS. Talon cusp: a prevalence study. J Indian Soc Pedod Prev Dent 1983;1:2834.

10. Hattab FN, Yassin OM, al-Nimri KS. Talon cusp in permanent dentition associated with other dental anomalies: review of literature and reports of seven cases. J Dent Child 1996;63:368-376.

11. Dhanrajani PJ. Hypodontia: etiology, clinical features and management. Quintessence Int 2002;33:294-302.

12. Schuurs AHB, van Loveren C. Double teeth: review of the literature. J Dent Child 2000;67:313-325.

13. Goldstein E, Medina JL. Mohr syndrome or oral-facial-digital II: report of two cases. J Am Dent Assoc 1974;89:377-382.

14. Chen RJ, Chen HS. Talon cusp in primary dentition. Oral Surg Oral Med Oral Pathol Oral Radiol Endod 1986;62:67-72.

15. Gardner DG, Girgis SS. Talon cusps: a dental anomaly in the Rubinstein-Taybi syndrome. Oral Surg Oral Med Oral Pathol Oral Radiol Endod 1979;47:519-521.

16. Salama FS, Hanes CM, Hanes PJ, Ready MA. Talon cusp; a review and two case reports on supernumerary primary and permanent teeth. J Dent Child 1990;57:147-149.

17. Tsutsumi T, Oguchi H. Labial talon cusp in a child with incontinentia pigmenti chromians: case report. Pediatr Dent 1991;13:236-237.

18. Happle R, Vakilzadeh F. Hamartomatous dental cusps in hypomelanosis of Ito. Cli Genet 1982;21:65-68.

19. Hattab FN, Yassin OM, Sasa IS. Oral manifestations of Ellisvan Creveld syndrome: report of two siblings with unusual dental anomalies. J Clin Pediatr Dent 1998;22:159-165.

20. Chatterjee M, Mason C.Talon cusps presenting in a child with Alagille's syndrome- a case report. J Clin Pediatr Dent 2007;32:61-63. 
21. Jernvall J, Thesleff I. Reiterative signalling and patterning during mammalian tooth morphogenesis. Mech Dev 2000;92:19-29.

22. Vastardis H, Karimbux N, Guthua SW, Seidman JG, Seidman CE. A human MSX 1 homeodomain missense mutation causes selective tooth agenesis. Nat Genet 1996;13:417421.

23. Danesh G, Schrijnemakers T, Lippold C, Schäfer E. A fused maxillary central incisor with dens evaginatus as a talon cusp. Angle Orthod 2007;77:176-180.

24. Dash JK, Sahoo PK, Das SN. Talon cusp associated with other dental anomalies. Int J Paed Dent 2004;14:295-300.

25. Hegde S, Kumar BRA. Mandibular talon cusp: report of two rare cases. Int J Paed Dent 1999;9:303-306.

26. Crawford NL, North S, Davidson LE. Double permanent incisor teeth: management of three cases. Dent Update 2006;33:608-610.

27. Hattab FN, Hazza'a AM. An unusual case of talon cusp on geminated tooth. J Can Dent Assoc 2001;67:263-266. 